\title{
Developmental speed affects ecological stoichiometry and adult fat reserves in Drosophila melanogaster
}

\author{
Indrikis A. Krams ${ }^{1,2,3,4, *}$, Ronalds Krams ${ }^{4,5}$, Priit Jõers $^{6}$, Māris Munkevics ${ }^{2,4}$, \\ Giedrius Trakimas ${ }^{7}$, Severi Luoto ${ }^{8,9}$, Sarah Eichler $^{10}$, David M. Butler ${ }^{11}$, \\ Enno Merivee ${ }^{4}$, Anne Must ${ }^{4}$, Markus J. Rantala ${ }^{12}$, Jorge Contreras-Garduño ${ }^{13}$ and \\ Tatjana Krama ${ }^{1,4,5}$ \\ ${ }^{1}$ Latvian Biomedical Research and Study Centre, Rìga 1067, Latvia \\ ${ }^{2}$ Department of Zoology and Animal Ecology, Faculty of Biology, University of Latvia, Riga 1004, \\ Latvia \\ ${ }^{3}$ Institute of Ecology and Earth Sciences, University of Tartu, 51010 Tartu, Estonia \\ ${ }^{4}$ Department of Biotechnology, Daugavpils University, 5401 Daugavpils, Latvia \\ ${ }^{5}$ Department of Plant Protection, Estonian University of Life Sciences, 51014 Tartu, Estonia \\ ${ }^{6}$ Department of General and Microbial Biochemistry, University of Tartu, 51010 Tartu, Estonia \\ ${ }^{7}$ Institute of Biosciences, Life Sciences Center, Vilnius University, 10223 Vilnius, Lithuania \\ ${ }^{8}$ English, Drama and Writing Studies, University of Auckland, 1142 Auckland, New Zealand \\ ${ }^{9}$ School of Psychology, University of Auckland, 1142 Auckland, New Zealand \\ ${ }^{10}$ Department of Biological Sciences, Kent State University, 44460 Salem, OH, USA \\ ${ }^{11}$ Department of Plant Sciences, University of Tennessee, 37996-4561 Knoxville, TN, USA \\ ${ }^{12}$ Department of Biology \& Turku Brain and Mind Centre, University of Turku, 20014 Turku, \\ Finland \\ ${ }^{13}$ Escuela Nacional de Estudios Superiores Unidad Morelia, Universidad Nacional Autónoma de \\ México, 58190 Morelia, Mexico
}

Submitted: January 3, 2020. Final revision received: April 7, 2020. Accepted: June 7, 2020

\begin{abstract}
The elemental composition of organisms belongs to a suite of functional traits that change during development in response to environmental conditions. However, associations between adaptive variations in developmental speed and elemental body composition are not well understood. We compared body mass, elemental body composition, food uptake and fat metabolism of Drosophila melanogaster male fruit flies in relation to their larval development speed. Slowly developing flies had higher body carbon concentration than rapidly developing and intermediate flies. Rapidly developing flies had the highest body nitrogen concentration, while slowly developing flies had higher body nitrogen levels
\end{abstract}

*) Corresponding author; e-mail: indrikis.krams@ut.ee 
than flies with intermediate speed of development. The carbon-to-nitrogen ratio was therefore lower in rapidly developing flies than in slow and intermediate flies. We also had a group of flies grown individually and their body mass and elemental body composition were similar to those of rapidly developing individuals grown in groups. This suggests that rapid growth is not suppressed by stress. Feeding rates were lowest in the slowly developing flies. The amount of triacylglycerides was highest in the flies with intermediate developmental speed which optimizes development under many climatic conditions. Although low food intake slows down developmental speed and the accumulation of body fat reserves in slowly developing flies, their phenotype conceivably facilitates survival under higher stochasticity of their environments. Rapidly developing flies grew with less emphasis on storage buildup. Overall, this study shoes that a combination of bet-hedging, adaptive tracking and developmental plasticity enables fruit flies to respond adaptively to environmental uncertainty.

\section{Keywords}

Carbon-to-nitrogen ratio; developmental speed; Drosophila melanogaster; ecological stoichiometry; larval development

\section{Introduction}

Biotic and abiotic environmental stressors affect organismal development, with impacts that are able to create individual and population differences in life history strategies (Adamo et al., 2012; Adamo \& McKee, 2017; Boonstra, 2013; Luoto et al., 2019a; Nettle \& Frankenhuis, 2019; Prokkola et al., 2013). During stress, the internal state of an organism falls outside the organism's typical operating range (Steinberg, 2012; van Straalen, 2003). Stress induces specific biochemical and physiological responses that counteract its consequences. Responses to adverse conditions represent cascades of internal changes to balance growth, reproduction, immune defense, self-maintenance and external stressors (Hawlena $\&$ Schmitz, 2010a). However, the availability of fitness-relevant resources in any particular environment is limited; time, effort and energy expended in any given way reduces their availability for other activities and biological processes (Sperfeld et al., 2017; Stearns, 1992). This often causes trade-offs in allocations of an individual's resources to such competing life functions as immunity, reproduction, self-maintenance, development and growth especially under conditions of stress (Krams et al., 2011; Leal et al., 2017; Luoto, 2019; Roff, 1992).

Ecological stoichiometry is a field of research that focuses on the interactions of organisms with their environments and the subsequent changes in the elemental composition of their bodies (Elser et al., 2000; Meunier et al., 2017; Sperfeld et al., 2017). Organisms can regulate their internal state by adjusting food intake and metabolism, which have the potential to affect the elemental composition of organisms (Trakimas et al., 2019). Several environmental factors are known to influence elemental composition of organisms, including pollution (De Senerpont Domis et al., 2014; Janssens et al., 2017), ambient temperature changes (Liess et al., 2013; Janssens et al., 2015; Schmitz, 2013; Zhang et al., 2016) and predation risk (Janssens et al., 2015; Krams et al., 2016; Van Dievel et al., 2016; Zhang et al., 2016). For example, predator-induced stress generally increases metabolic rate 
(Hawlena \& Schmitz, 2010a, b; Slos \& Stoks, 2002; Krams et al., 2013a, b). Consequently, rising energetic demands increase the overall demand for carbohydratebased fuel and shift the metabolic balance away from anabolism that produces nitrogen-rich $(\mathrm{N})$ proteins necessary for growth (Hawlena \& Schmitz, 2010a, b). Under such circumstances, the body utilizes proteins to produce glucose (Hawlena \& Schmitz, 2010a). However, this is not a universal condition: for example, common fruit flies (Drosophila melanogaster Meigen, 1830), reared together with spiders had increased concentration of body $\mathrm{N}$ and lower body mass, while their body carbon (C) remained the same as in control individuals (Krams et al., 2016). These stoichiometric changes improved climbing speed and adult survivorship under experimentally induced predation risk (Krams et al., 2016). This may represent bet-hedging in anti-predator defense whereby stress promotes fitness better than it does in a typical (safer) environment.

It has been suggested that growth rates will always be at their physiological maximum unless there exists some intrinsic cost of rapid growth (Abrams \& Rowe, 1996). However, evidence shows that few organisms develop at their maximum growth rate (Fischer et al., 2005; Kecko et al., 2017; Shakarad et al., 2001, 2005). The pace-of-life syndrome (POLS) hypothesis (Debecker \& Stoks, 2019; Mathot \& Frankenhuis, 2018; Réale et al., 2010) predicts that rapidly developing individuals with high activity have faster life histories (e.g., faster development and earlier reproduction) and higher metabolic rate, which increase resource acquisition (Réale et al., 2010) and reduce life span through increased oxidative damage (Janssens \& Stoks, 2018). Importantly, the growth rate hypothesis (GRH) predicts that rapidly growing organisms have higher concentrations of body $\mathrm{N}$ because of increased synthesis of N-rich proteins (Elser et al., 2000; Sterner \& Elser, 2002). On the other hand, rapid development can be adaptive because of bet-hedging, which promotes survival and reproduction under transient environmental changes (Haccou \& Iwasa, 1995; Müller et al., 2013). In bet-hedging, a single genotype produces an array of phenotypes: this risk-spreading strategy guarantees that some phenotypes optimally match the environment (Levy et al., 2012). For example, it has been shown that an optimal strategy of the desert plant is to improve survival by hedging its bets and having seeds that start their growth as early as they can while the others germinate only under the most suitable conditions (Cohen, 1966). Bet-hedging may be especially useful in $D$. melanogaster, an $r$-selected species that has a relatively short generation time in relation to seasonal temperature fluctuations and the availability of resources. In D. melanogaster, another strategy to cope with environmental uncertainty is adaptive tracking where individuals survive changing conditions by having diversified phenotypes as a result of genetic variation. Adaptive tracking has the potential to outcompete bet-hedging only under conditions of stable climate and predictable resource access (Kain et al., 2012).

Surprisingly, slow development may also incur costs (Krams et al., 2018). Slower development has been associated with upregulation of stress-related genes (Gutiérrez-Adán et al., 2004). It has also been shown that wings of late-hatched 
female damselflies, Lestes viridis Vander Linden, 1825, are less symmetrical than those of early-hatched individuals, suggesting that late-hatched female damselflies experience developmental stress (De Block et al., 2008). A recent study reported high $\mathrm{N}$ concentrations in the bodies of rapidly developing crickets (Trakimas et al., 2019), supporting the GRH (Elser et al., 2000; Sterner \& Elser, 2002). However, slowly developing crickets had significantly higher body $\mathrm{C}$ and higher $\mathrm{C} / \mathrm{N}$ ratio (both are indicators of stress) than rapidly developing crickets, a finding that suggests higher stress levels in slowly growing individuals (Trakimas et al., 2019). This may be because individuals that grow slower than conspecifics risk finishing their larval development in environments that are polluted with nitrogenous metabolic waste left by rapidly developing individuals. It has been shown that $D$. melanogaster individuals that eclose later than rapidly and intermediately growing ones have increased tolerance to urea/ammonia, which requires time and energy investment to develop specific biochemical adaptations (Borash et al., 1998; Prasad et al., 2000). It therefore has the potential to increase physiological stress in slowly developing individuals.

In this study we investigated concentrations of body $\mathrm{C}, \mathrm{N}$ and the $\mathrm{C} / \mathrm{N}$ ratio in D. melanogaster adult flies with slow, intermediate and rapid developmental speed during larval development. Developmental time is a trait of significant relevance to fitness especially in Drosophila species (Mensch et al., 2008). Fruit flies often occupy ephemeral habitats such as rotting fruits, which may promote rapid larval development as fruits dry out. However, selection for faster development and early reproduction leads to a reduction in egg-to-eclosion development time, survivorship, lower adult dry body mass at eclosion and a decline in larval growth rate (Prasad et al., 2000). Therefore, we did not use selective lines and did not manipulate the presumed causal factors of growth experimentally but took advantage of naturally occurring variation in studying the effects of elemental composition and body mass in male fruit flies across the time gradient of their larval development. We also investigated feeding rates and fat reserves of fruit flies from three different developmental groups. This was done because rapidly developing individuals are generally considered to consume more food to grow faster than slowly growing individuals (Prasad \& Joshi, 2003). Based on prior research (Trakimas et al. 2019), we predicted higher feeding rates, higher body $\mathrm{N}$, lower $\mathrm{C}$ and lower $\mathrm{C} / \mathrm{N}$ ratio in rapidly developing flies. With regard to bet-hedging in developmental speed (Solopova et al., 2014), we predicted low fat reserves in rapidly and slowly developing flies because fat may be used to sustain high growth rates in the former individuals and to enable specific physiological survival mechanisms in deteriorated environments in the latter individuals (Krams et al., 2016). We also studied fruit flies that were grown individually in vials to see how the absence of intraspecific competitors affects their developmental time, body mass and body composition. We studied only males because a sizable fraction of the body of a mated female is made up of developing eggs, which have a significantly different metabolism than 
the female soma (Burggren et al., 2017). Therefore, using females would lead to obfuscated results with regard to adult stoichiometry.

\section{Methods}

\section{Insects and development groups}

Fruit flies were maintained in a lab at the University of Tennessee-Knoxville at $22.5 \pm 1{ }^{\circ} \mathrm{C}$ under a constant $12: 12 \mathrm{~h}$ light-dark cycle. The wild strains OregonR-modENCODE (\#25211) of D. melanogaster were obtained from Bloomington Drosophila Stock Center (Indiana University, Bloomington, IN, USA).

The flies were isolated under carbon dioxide anaesthesia. To ensure virginity, we isolated females within $7 \mathrm{~h}$ after imaginal eclosion. All flies used to produce progeny eclosed themselves on day 12.0-12.5. To obtain fruit flies for this study, we placed ten females and ten males per vial ( $N=22$; Flystuff polystyrene vials; Genesee Scientific, El Cajon, CA, USA, $24 \mathrm{~mm}$ inner diameter $\times 95 \mathrm{~mm}$ height) with $6 \mathrm{ml}$ of food (cornmeal, dextrose and yeast medium) to copulate for 9-10 h. Anaesthesia was not used for this part of the study. We subsequently removed all females from vials and moved them to other vials of the same size and food volume $(6 \mathrm{ml})$ for $1 \mathrm{~h}$ to oviposit. Food was cooked as a mixture of $500 \mathrm{ml}$ water, $25 \mathrm{~g}$ dextrose, $12 \mathrm{~g}$ sucrose, $10 \mathrm{~g}$ brewer's yeast, $35 \mathrm{~g}$ cornmeal, $4.5 \mathrm{~g}$ agar and $12.5 \mathrm{ml}$ of a Tegosept (methyl- $p$-hydroxy benzoate) (Genesee Scientific, El Cajon, CA, USA,) stock solution. For the Tegosept stock solution, $50 \mathrm{~g}$ of Tegosept were dissolved in $500 \mathrm{ml}$ of $95 \%$ ethanol. This recipe is adapted from that of Cold Spring Harbor Protocols (Lewis, 2014).

When the eggs began to hatch, we collected 10 flies of each of the following groups: (1) most rapidly developing flies, (2) most slowly developing flies, and (3) flies that developed with intermediate speed. We collected a total of 30 flies per each vial. We used individuals with intermediate speed of development as controls to the rapid development and slow development groups. The most rapidly developing flies eclosed on day 9 (females laid eggs on day 0 ), the most slowly developing flies were collected on day 15, while we considered flies eclosing on day 12 as the intermediate group. Specifically, the group of rapidly developing flies consisted of individuals that eclosed between 9.5 and 10.0 days, the intermediate group consisted of flies that eclosed between 11.5 and 12.5 days and the group of slowly developing flies consisted of individuals that eclosed between 14.5 and 15 days. Although developmental time of D. melanogaster is highly variable (Bharathi et al., 2004), it is generally overlooked that the eclosion period of fruit flies may be much longer and the final flies often eclose several days later than the first ones (Bierbaum et al., 1989).

Each vial contained between 75 and 80 larvae. This number is considered to represent low to average density of offspring for this vial size (Bierbaum et al., 1989; Horváth \& Kalinka, 2016), suggesting the larvae did not experience severe competition for food and space as opposed to normal lab conditions where more 
than 150 larvae usually live in $24 \times 95 \mathrm{~mm}$ vials. Removal of eclosing fruit flies affected the density of remaining larvae. To keep the density constant, we added a corresponding number of larvae and fresh food to each vial. Although the larvae were provided with fresh food ad libitum until the final day of their development, we did not remove any products of fly metabolism. This means that the concentration of N-rich fecal material continuously increased, and slowly growing flies finished their development in the most spoiled environment. The quality of food (spoiled by metabolic waste) may trigger the development of different biochemical phenotypes (Krams et al., 2015).

We also had 100 fruit flies which developed singly. Only one egg was placed in each $24 \times 95 \mathrm{~mm}$ vial. We recorded imaginal eclosion time and body composition of these individuals. Imaginal eclosion of singly grown fruit flies was observed every $3 \mathrm{~h}$. Similar timeframes have been used in other studies (Lin et al., 2011).

\section{Fruit fly body $C$ and $N$ content}

Within 6-8 $\mathrm{h}$ after imaginal eclosion, each fly was placed separately in vials for $1 \mathrm{~h}$ with only water and no food provided. This ensured all consumed food and faeces were released during the fasting period. Then the flies were frozen at $-80^{\circ} \mathrm{C}$. On the next day, the flies were dried at $75^{\circ} \mathrm{C}$ for $72 \mathrm{~h}$, and weighed as groups of 10 males (Vijiendravarma et al., 2011) using a Sartorius (Göttingen, Germany) MC5 microanalytical balance with an accuracy of $\pm 1 \mu \mathrm{g}$. Dry body weight was calculated for individual flies as the dry mass of each replicate divided by the number of flies assigned in each replicate. Each group of 10 individuals was ground to a homogenous powder.

The percentage of $\mathrm{C}$ and $\mathrm{N}$ content was measured from the mass of whole flies using a C/N combustion auto-analyser (Hawlena \& Schmitz, 2010a, b; Krams et al., 2016). Samples of $C$ and $N$ concentrations were measured as groups of 10 fruit flies equally representing each vial. In total, we measured 220 males for each developmental speed, with a total of 660 flies. We also measured 10 samples (10 fruit flies in each sample) of flies grown singly.

\section{Food uptake}

We used additional six vials to collect three-day-old fruit flies for feeding experiments. For each experiment, 150 flies were distributed to six separate vials (25 flies per vial) with standard food (Bahhir et al., 2019). The flies were allowed to recover overnight from $\mathrm{CO}_{2}$ exposure. On the next day we transferred the flies to new vials without using gas. We transferred half of the flies to vials with standard food, whereas the other half was transferred to vials with food supplemented with $1 \%$ Blue FCF dye (Thermo Fisher Scientific, Waltham, MA, USA). After 1.5 h, 20 flies were collected and lysed by grinding in a mortar and pestle in $800 \mu \mathrm{l}$ of phosphatebuffered saline (PBS) (Bahhir et al., 2019). Debris was pelleted at $10000 \mathbf{g}_{\max }$ for $10 \mathrm{~min}$ at $4{ }^{\circ} \mathrm{C}$ and supernatant was transferred to fresh Eppendorf tubes with- 
out disturbing the pellet. Supernatant was centrifuged again as above, after which $400 \mu \mathrm{l}$ of each supernatant were transferred to two wells (200 $\mu \mathrm{l}$ each) of 96-well plates. Absorbance of lysate was measured at $650 \mathrm{~nm}$ with a Tecan Infinite M200 Pro spectrophotometer (Tecan Group Ltd, Männedorf, Switzerland) and amount of Blue FCF ingested was calculated using serial dilution of Blue FCF as a calibrator (Bahhir et al., 2019). There were seven vials for the rapid development group, five vials for the intermediate group and six vials for the slow development group.

\section{Total glycerol measurements}

Ten flies were homogenized inside an Eppendorf tube in $400 \mu \mathrm{l}$ of PBS and $0.1 \%$ Tween 20 (Bahhir et al., 2019; Barrio et al., 2014). Lysate was heat-treated at $70^{\circ} \mathrm{C}$ for $5 \mathrm{~min}$ to denature proteins after which two $20 \mu \mathrm{l}$ aliquotes were mixed with $20 \mu 1$ Triglyceride Reagent (Sigma T2449) (Merck KGaA, Darmstadt, Germany) and one $20 \mu \mathrm{l}$ aliquot was mixed with $20 \mu \mathrm{l}$ of PBS and incubated at $37^{\circ} \mathrm{C}$ for $30 \mathrm{~min}$. During the incubation time, protein concentration in lysate was determined with the Bradford assay. After incubation, samples were centrifuged for $15 \mathrm{~s}$ at $14000 \mathbf{g}_{\max }$ and $30 \mu \mathrm{l}$ was transferred to a 96-well plate. PBS-treated samples were mixed either with $100 \mu$ l of Free Glycerol Reagent (Sigma F6428, determination of free glycerol) or water (background) and Triglyceride Reagent-treated samples were mixed with $100 \mu \mathrm{l}$ of Free Glycerol Reagent (determination of total glycerol). Plates with samples were incubated at $37^{\circ} \mathrm{C}$ for $5 \mathrm{~min}$ and the amount of quinonemine dye was measured with a spectrophotometer at $540 \mathrm{~nm}$ (Bahhir et al. 2019; Barrio et al., 2014). The results (normalized against protein content) are presented as arbitrary units (a.u.).

\section{Statistics}

We used one-way analyses of variance (ANOVAs) to compare individual body mass, elemental composition, total glycerol and food uptake in developmental groups of fruit flies. We used developmental group (rapid, intermediate, slow) as a fixed factor. We report only main effects if we did not find a significant difference between developmental groups; otherwise, we also report Tukey' Honest Significant Difference (HSD). We compared elemental body composition and body mass between flies grown in groups and singly using $t$-tests. We used Levene's test to determine the equality of variances. We applied natural log transformation to carbon-to-nitrogen ratio values before ANOVA to avoid heteroscedasticity. Analyses were performed using R, version 3.5.2 (R Core Team, 2018). Group differences were considered statistically significant at $P<0.05$.

\section{Results}

Body mass

Body mass of males in the three developmental groups was heterogeneous (one-way ANOVA: $\left.F_{2,63}=60.08, P<0.0001\right)$. While rapidly developing males $(0.23 \pm$ 

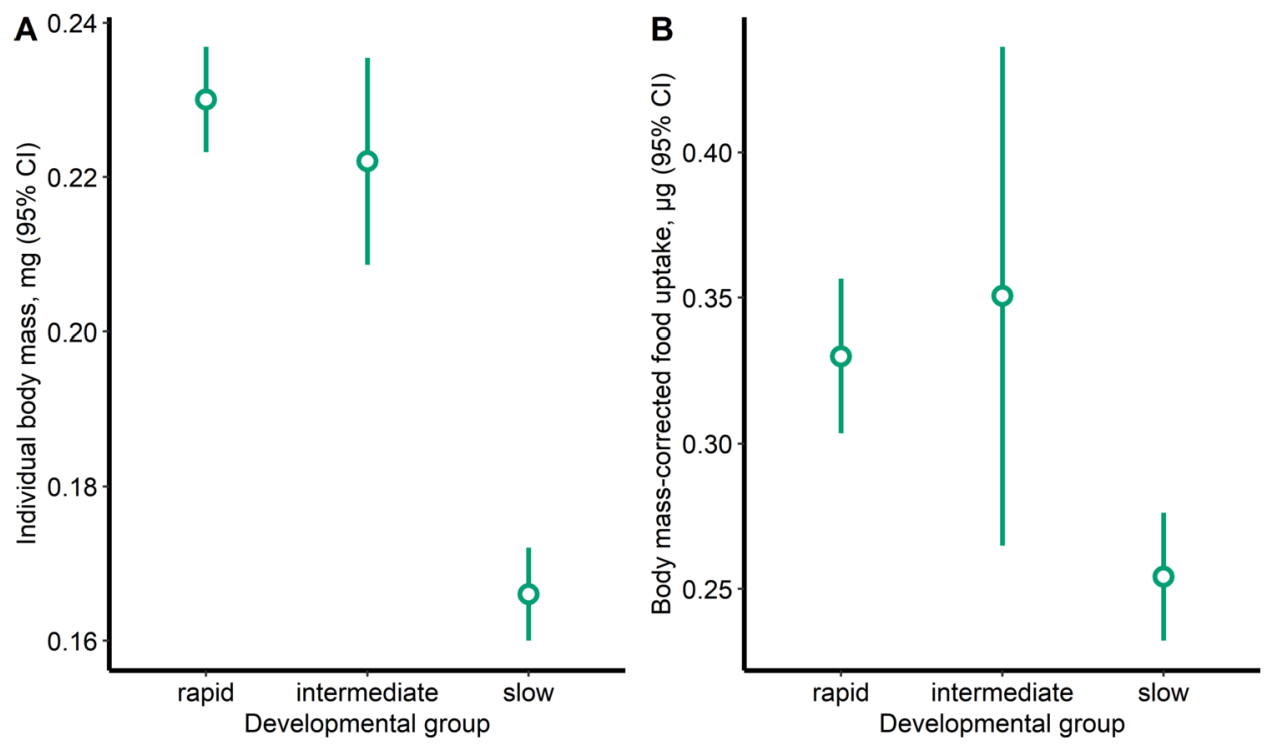

Figure 1. (A) The average dry body mass of male fruit flies. (B) Body-mass-corrected food uptake of fruit flies in rapid, intermediate and slow development groups. Error bars represent $95 \%$ confidence intervals.

$0.02 \mathrm{~g}$; mean $\pm \mathrm{SD}$ ) did not differ (Tukey HSD: $P=0.43$ ) in their dry body mass from males in the intermediate development group $(0.22 \pm 0.03 \mathrm{~g}$; mean $\pm \mathrm{SD})$, males in both of these groups were significantly heavier (Tukey HSD: both $P$ s < $0.0001)$ than males in the slow development group $(0.17 \pm 0.01 \mathrm{~g}$; mean $\pm \mathrm{SD}$; fig. 1A).

Body mass of singly grown males $(0.23 \pm 0.004 \mathrm{~g}$; mean $\pm \mathrm{SD})$ did not statistically differ from body mass of males in the rapid development group $(t=0.23$, $\mathrm{df}=$ $30, P=0.82)$ and intermediate development group $(t=0.71, \mathrm{df}=30, P=0.48)$. Body mass of singly grown males significantly differed from body mass of males in the slow development group $(t=14.26, \mathrm{df}=30, P<0.0001)$.

\section{Body mass-corrected food uptake}

The developmental groups significantly differed in their food uptake (one-way ANOVA: $\left.F_{2,15}=16.60, P=0.0015\right)$. Although the food uptake of rapidly developing flies $(0.33 \pm 0.029$; mean $\pm \mathrm{SD})$ did not differ significantly from food uptake of the intermediate group $(0.35 \pm 0.07$; mean $\pm \mathrm{SD})$ (Tukey HSD: $P=0.69)$, flies with rapid and intermediate development significantly differed from slowly developing flies $(0.25 \pm 0.02$; mean $\pm \mathrm{SD}$ ) (Tukey HSD: $P=0.014$ and $P=0.0046$, respectively; fig. 1B). 

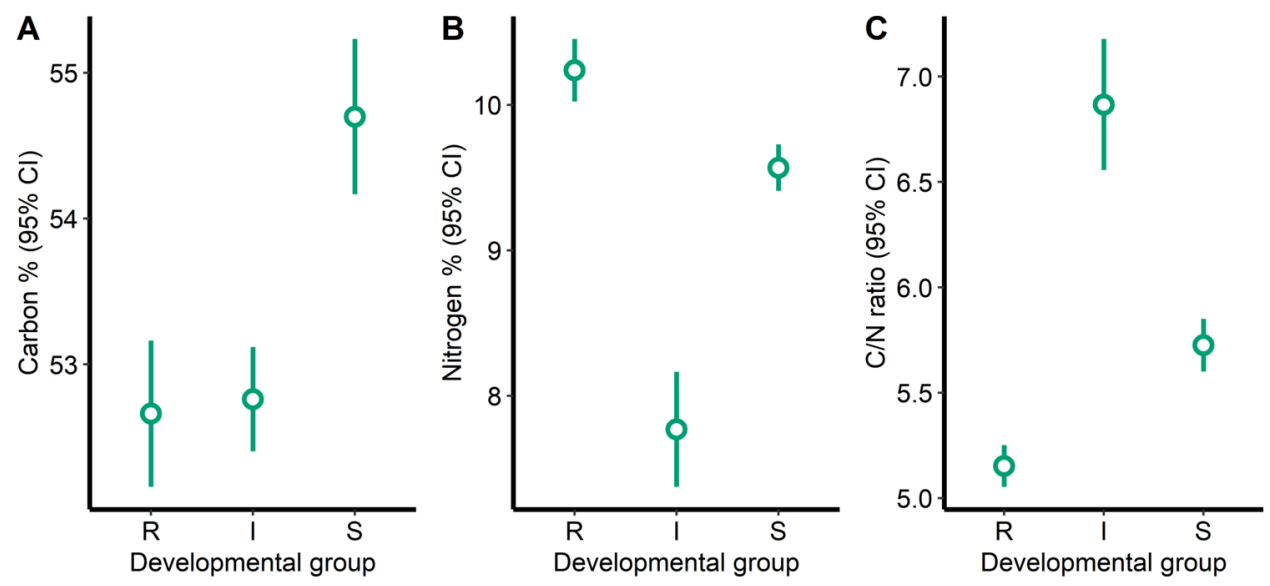

Figure 2. (A) Average carbon, (B) average nitrogen percentage and (C) average carbon-to-nitrogen ratio $(\mathrm{C} / \mathrm{N}$ ratio) in adult $D$. melanogaster of rapid development $(\mathrm{R})(n=22)$, intermediate development (I) $(n=22)$ and slow development $(\mathrm{S})(n=22)$ groups. Error bars represent $95 \%$ confidence intervals.

\section{Carbon}

There was a statistically significant difference between developmental groups in body $\mathrm{C}$ (one-way ANOVA: $F_{2,63}=25.77, P<0.0001$ ). Slowly developing fruit flies had higher body $\mathrm{C}(\%)(54.70 \pm 1.20$; mean $\pm \mathrm{SD})$ than rapidly developing $(52.66 \pm 1.13)$ and intermediate $(52.76 \pm 0.81)$ fruit flies (Tukey HSD: all $P$ s $<$ $0.0001)$. Fruit flies in the rapid and intermediate development groups did not differ in body $\mathrm{C}(P=0.95$; fig. $2 \mathrm{~A})$.

Body $\mathrm{C}(\%)$ of singly grown flies $(52.50 \pm 0.65$; mean $\pm \mathrm{SD})$ did not statistically differ from body $\mathrm{C}$ of flies in the rapid $(t=0.43, \mathrm{df}=30, P=0.67)$ and intermediate development groups $(t=0.91, \mathrm{df}=30, P=0.37)$. Slowly developing fruit flies had higher body $\mathrm{C}$ than the singly grown flies $(t=5.41, \mathrm{df}=30, P<0.0001)$.

\section{Nitrogen}

The effect of developmental group on body $\mathrm{N}$ was significant (one-way ANOVA: $\left.F_{2,63}=92.87, P<0.0001\right)$. Rapidly developing flies had higher body $\mathrm{N}(\%)$ $(10.24 \pm 0.49$; mean \pm SD) than slowly developing $(9.569 \pm 0.360)$ and intermediate (7.77 \pm 0.89$)$ flies (Tukey HSD: $P<0.01$ and $P<0.0001$, respectively). Fruit flies in the slow and intermediate development groups differed in their body N (Tukey HSD: $P<0.0001$; fig. 2B).

Body $\mathrm{N}(\%)$ of singly grown flies $(10.47 \pm 0.57$; mean \pm SD) did not statistically differ from body $\mathrm{N}$ of flies in the rapid development group $(t=1.20$, $\mathrm{df}=30$, $P=0.24)$. Singly grown males had higher body $\mathrm{N}$ than flies in the intermediate developmental $(t=8.76, \mathrm{df}=30, P<0.0001)$ and slow development groups $(t=$ 5.46, df $=30, P<0.001)$. 

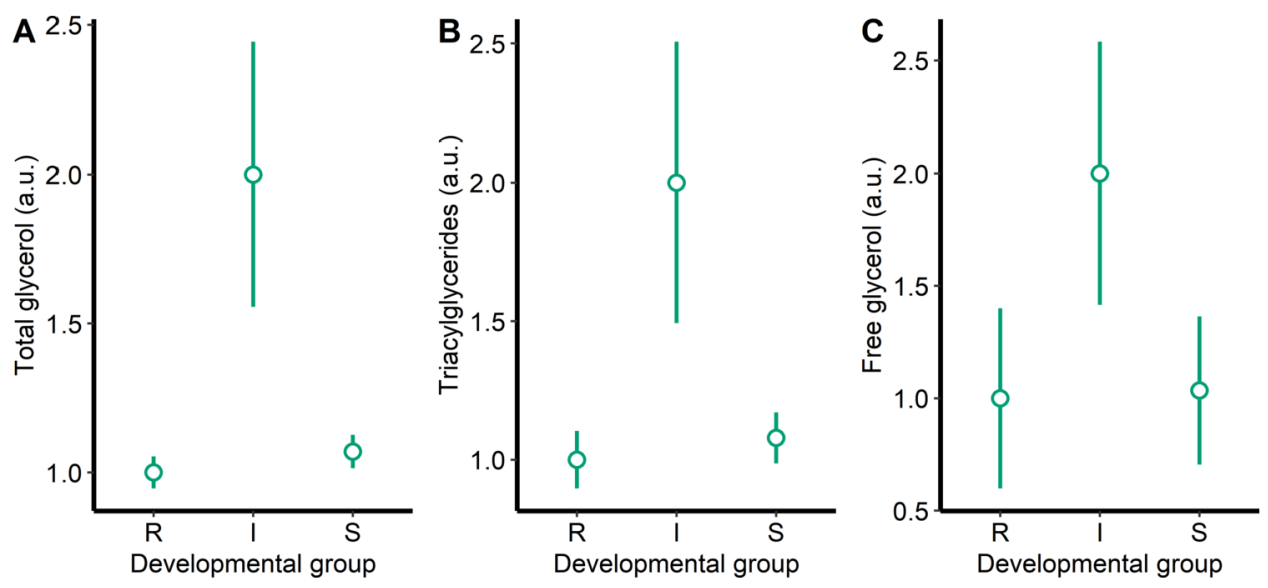

Figure 3. Total glycerol (A), triacylglycerides (B) and free glycerol (C) in rapid (R), intermediate (I) and slow $(\mathrm{S})$ development fruit flies. Error bars represent $95 \%$ confidence intervals.

\section{C/N ratio}

The effect of developmental group was significant (one-way ANOVA: $F_{2,63}=$ 79.40, $P<0.0001)$. Rapidly developing fruit flies had lower $\mathrm{C} / \mathrm{N}$ ratio $(5.15 \pm$ 0.22 ; mean $\pm \mathrm{SD})$ than slowly developing $(5.73 \pm 0.28)$ and intermediate $(6.87 \pm$ 0.70) fruit flies (Tukey HSD: $P<0.001$ and $P<0.0001$, respectively). Fruit flies in the slow and intermediate development groups also differed in their $\mathrm{C} / \mathrm{N}$ ratio $(P<0.0001$; fig. 2C).

The $\mathrm{C} / \mathrm{N}$ ratio of singly grown fruit flies $(5.03 \pm 0.25$; mean $\pm \mathrm{SD})$ did not statistically differ from that in males of the rapid development group $(t=1.45$, $\mathrm{df}=$ $30, P=0.16)$. The singly grown males had lower $\mathrm{C} / \mathrm{N}$ ratio than slowly developing $(t=6.74$, df $=30, P<0.0001)$ and intermediate fruit flies $(t=8.01, \mathrm{df}=30$, $P<0.0001)$.

\section{Fat metabolism}

The effect of developmental group on total glycerol was significant (one-way ANOVA: $F_{2,12}=35.5, P<0.0001$ ). Total glycerol (normalized to total protein) in rapidly $(1.00 \pm 0.04)$; mean $\pm \mathrm{SD})$ and slowly $(1.07 \pm 0.05)$ developing flies was lower than in intermediate $(2.00 \pm 0.36)$ flies (Tukey HSD: both $P_{\mathrm{S}}<0.0001$; fig. 3A).

The effect of developmental group on storage fats was significant (one-way ANOVA: $\left.F_{2,12}=25.93, P<0.0001\right)$. Triacylglycerides (normalized to total protein) in both rapidly (1.00 \pm 0.08 ; mean \pm SD) and slowly developing flies (1.08 \pm $0.07)$ were lower than in the intermediate group $(2.00 \pm 0.41)$ flies (Tukey HSD: $P<0.0001$ and $P<0.001$, respectively; fig. 3B).

The effect of developmental group on free glycerol in fruit flies was significant (one-way ANOVA: $F_{2,12}=12.2, P<0.01$ ). Free glycerol (normalized to total 
protein) was also lower in both rapidly $(1.00 \pm 0.32$; mean \pm SD) and slowly $(1.03 \pm 0.27)$ developing flies (Tukey HSD: both $P_{\mathrm{s}}<0.01$; fig. 3C) compared to flies in the intermediate development group $(2.00 \pm 0.47)$.

\section{Developmental time of singly grown fruit flies}

Imaginal eclosion of singly grown fruit fly males was observed between 9.25 and 12.25 days. Thirty-five flies eclosed on day 9, 49 flies eclosed on day 10, 13 flies on day 11 and 3 flies on day 12. In this study, we could not directly compare between developmental time of the singly grown flies and flies in the groups of rapid, intermediate and slow development. These free groups were chosen arbitrarily and each group was represented by flies which eclosed during one day. However, the majority of singly grown flies eclosed during days 9 and $10(n=84,84 \%)$ which corresponds to the rapid-to-intermediate pace of development in this study.

\section{Discussion}

The whole life cycle of $D$. melanogaster from egg to adult is variable and normally takes between 9 and 12 days. In this study, most fruit flies eclosed around days $10.0-11.5$ at $25^{\circ} \mathrm{C}$ with a tiny proportion of flies eclosing on day 14 . Our results show that this considerable variation in the developmental time of fruit flies is associated with substantial between-individual variation in food uptake and body mass, the elemental composition and fat reserves of their bodies under conditions of the deterioration of the environment. The findings reported here are consistent with a recent study on the effects of developmental speed on the stoichiometry of crickets (Gryllus integer Scudder, 1902) (Trakimas et al., 2019). Because of the high variability of eclosion time, average larval density and other conditions kept relatively constant, our results indicate that developmental plasticity and adaptive tracking alone cannot explain the observed variability of phenotypes. We suggest that the observed variation in developmental time is a result of a combination of plasticity, adaptive tracking and bet-hedging (Kain et al., 2015; Leal et al., 2017; Svardal et al., 2011).

Although rapidly growing fruit flies developed for the shortest time, these flies were heavier than slowly developing ones. The high developmental speed is explained by the high feeding rates and low triacylglyceride levels of rapidly developing flies (Prasad \& Joshi, 2003). Importantly, high body N, low C and low C/N ratio suggest that rapidly developing fruit flies experienced low levels of stress, a finding that appears to contradict results from a number of studies which show that rapid growth is costly (Gotthard et al., 1994; Nylin et al., 1996; Lankford et al., 2001; Fischer et al., 2005). Our results suggest that growth rates in rapidly growing D. melanogaster are optimized rather than maximized and that these rates most likely do not operate near their physiological maximum (Roff, 1992; Stearns, 1992; Stearns \& Koella, 1986) where rapid growth causes oxidative stress and other costs (Bayliak et al., 2019; Fischer et al., 2005; Güneş, 2020; Kecko et al., 2017; Slos \& 
Stoks, 2002). Importantly, singly grown flies whose development was not affected by intraspecific competition eclosed rapidly and their body mass, body $\mathrm{C}$, body $\mathrm{N}$ and the $\mathrm{C} / \mathrm{N}$ ratio did not differ from these parameters of flies in the rapid development group. This idea of higher stress in slowly developing flies is further supported by the finding that rapid development in selective lines is associated with low adult body mass only upon selection (Prasad et al., 2000).

Slowly developing fruit flies had significantly higher body $\mathrm{C}$, lower $\mathrm{N}$ and higher $\mathrm{C} / \mathrm{N}$ ratio than rapidly developing flies and singly grown flies. This finding suggests that slowly developing flies are under higher stress levels during their larval development than rapidly developing and singly grown flies. Stress is supposed to increase metabolic rate (Peckarsky et al., 2008; Krams et al., 2017; Trakimas et al., 2019) and energetic demands by raising the need for carbohydrate fuel. This increases body $\mathrm{C}$ content and lowers $\mathrm{N}$ because stress responses require the breakdown of body proteins to produce C-rich glucose (Christianson \& Creel, 2010; Hawlena \& Schmitz, 2010a, b). However, our results do not fully support previous findings of stress ecology (Peckarsky et al., 2008; Preisser \& Bolnick, 2008; Siepielski et al., 2014) because rapidly developing flies had low body $\mathrm{N}$ and low body C. Importantly, the feeding rate of slowly developing males was the lowest of all three groups, while their body $\mathrm{N}$ was significantly higher than that of flies in the intermediate development group. The $\mathrm{C} / \mathrm{N}$ ratio of slowly developing flies was lower, and their body $\mathrm{C}$ was higher than in the intermediate development group. Our results indicate that the high body $\mathrm{N}$ lowered the $\mathrm{C} / \mathrm{N}$ ratio of slowly developing flies compared to the intermediate development group. Although it is possible that high $\mathrm{C} / \mathrm{N}$ ratio in slowly developing flies was caused by low fat reserves, this does not explain the high body $\mathrm{C}$ concentrations in these flies. Overall, this shows that the observed simultaneous increase in $\mathrm{C}$ and $\mathrm{N}$ may render the $\mathrm{C} / \mathrm{N}$ ratio a less reliable stress indicator than in such cases where the concentration of only one element substantially changes in response to environmental changes.

It is important to understand possible reasons for the heightened $\mathrm{N}$ content in slowly developing flies given their low food uptake, small sizes and high body C. It has been shown that slow development usually results in deteriorated larval environment because of higher conspecific density, the presence of larger rapidly developing larvae and relatively higher levels of metabolic waste left by more rapidly developing larvae and slow developing flies themselves (Borash et al., 1998; Joshi \& Mueller, 1988; Shiotsugu et al., 1997). Slowly developing flies need to create specific biochemical/physiological adaptations against increased toxicity in their environment. Previous work has demonstrated that populations reared under crowded larval conditions evolve increased resistance to both urea and ammonia (Joshi et al., 1996; Somero \& Yancey, 1997), which has the potential to affect body composition of slowly developing flies. However, flies need selection to reach increased resistance to metabolic waste (Prasad \& Joshi, 2000). It is not clear whether the relatively low larval density in our study was enough to impair food quality: we therefore cannot ascertain that slower development was induced as an insurance 
against an unavoidable increase of urea/ammonia in the food/environment of slowly developing flies in our study.

Urea and ammonia have cytotoxic effects on D. melanogaster. Urea is a protein denaturant (Borash et al., 2000) and larvae reared on urea-containing media have increased levels of proteins containing isoaspartyl residues which itself can be responsible for the increased concentration of body $\mathrm{N}$ in slowly growing flies (David et al., 1999). Ammonia is known to have neurotoxic properties (Cooper \& Plum, 1987). It accumulates to significant levels in larval cultures (Borash et al., 1998), which makes ammonia a potential candidate for the observed high levels of body $\mathrm{N}$ in slowly developing flies. Moreover, the expression of specific adaptations to develop and live in toxic environments requires the production of protein cosolutes that act as cytoprotectants (Scherer, 2013). These substances may maintain high body $\mathrm{N}$ in slowly developing flies via their protein stabilizing effects (Yancey \& Siebenaller, 2015). Future studies on fruit fly adaptations have to focus not only on protein presence but also on proteostasis. Finally, urea may be used as an important $\mathrm{N}$ source and it can be assimilated through symbiotic interactions with a variety of ureolytic microorganisms (Stewart \& Smith, 2005). Thus, bacteria harvesting intestinal urea may also be responsible for the accumulation of $\mathrm{N}$ and the heightened body $\mathrm{N}$ in slowly developing flies.

The conditions experienced during larval growth and metamorphosis are important because neural and other physiological systems are under development and can be shaped by different types of stress (Spencer, 2017). The expression of bethedging and the developmental channeling of organisms into rapid or slow growth may cause permanent changes and lead to functionally coordinated sets in a range of phenotypic traits that benefit from the synergistic coordination of such traits (Healy et al., 2019; Leal et al., 2017; Wright et al., 2019). In this study, we show that differences in developmental speed in fruit flies result in differences in body mass, $\mathrm{C}$ and $\mathrm{N}$ content and $\mathrm{C} / \mathrm{N}$ ratio, food uptake, body mass and the amount of fat reserves. This knowledge may contribute to research on 'developmental programming', since variation in developmental speed can be a mechanism that creates phenotypes which are maximized for fitness (Holmes et al., 2015; Monaghan, 2008; Spencer, 2017; Trakimas et al., 2019). Our results also highlight the need to assess the concentration of body phosphorus to better understand the observed variations of $\mathrm{C}$ and $\mathrm{N}$ in D. melanogaster: phosphorus is important for RNA production and serves (quantified as the RNA:DNA ratio) as a proxy for protein synthesis (Janssens et al., 2017) and other life-supporting processes such as memory (Korneev et al., 2018).

Taken together, our findings suggest that developmental speed is an important variable influencing elemental composition and that both developmental speed and stoichiometry belong to a broader suite of life history traits (Leal et al., 2017; Luoto et al., 2019b; Maner et al., 2017). Overall, this study indicates that a combination of biochemical, physiological, ecological, dietary and behavioral approaches (Healy et al., 2019; Maner et al., 2017; Trakimas et al., 2019; Wright et al., 2019) is required 
to further develop the general stress paradigm, while focusing on ecological stoichiometry can provide an improved understanding of the dynamic ways in which organisms adapt to evolutionary selection pressures. Finally, the results of this study show that developmental speed needs to be taken into account when predicting the flow of energy through food chains in ecosystems affected by climate change (van de Waal et al., 2010; Van Dievel et al., 2019).

\section{Acknowledgements}

This work was supported by Fulbright Program of the Department of State of the US, the Latvian Council of Science (lzp-2018/1-0393) and a personal grant (PUT1223) from the Estonian Research Council.

\section{References}

Abrams, P.A. \& Rowe, L. (1996) The effects of predation on the age and seize of maturity of prey. Evolution, 50, 1052-1061. DOI:10.1111/j.1558-5646.1996.tb02346.x.

Adamo, S.A. \& McKee, R. (2017) Differential effects of predator cues versus activation of fight-orflight behaviour on reproduction in the cricket Gryllus texensis. Anim. Behav., 134, 1-8. DOI:10. 1016/j.anbehav.2017.09.027.

Adamo, S.A., Baker, J.L., Lovett, M.M.E. \& Wilson, G. (2012) Climate change and temperate zone insects: the tyranny of thermodynamics meets the world of limited resources. Environ. Entomol., 41, 1644-1652. DOI:10.1603/EN11188.

Bahhir, D., Yalgin, C., Ots, L., Järvinen, S., George, J., Naudí, A., Krama, T., Krams, I., Tamm, M., Andjelković, A., Dufour, E., González de Cózar, J.M., Gerards, M., Parhiala, M., Pamplona, R., Jacobs, H.T. \& Jõers, P. (2019) Manipulating mtDNA in vivo reprograms metabolism via novel response mechanisms. PLoS Genet., 15, e1008410. DOI:10.1371/journal.pgen.1008410.

Barrio, L., Dekanty, A. \& Milán, M. (2014) MicroRNA-mediated regulation of Dp53 in the Drosophila fat body contributes to metabolic adaptation to nutrient deprivation. Cell Rep., 8, 528541. DOI:10.1016/j.celrep.2014.06.020.

Bayliak, M.M., Abrat, O.B., Storey, J.M., Storey, K.B. \& Lushchak, V.I. (2019) Interplay between diet-induced obesity and oxidative stress: comparison between Drosophila and mammals. Comp. Biochem. Physiol. A, 228, 18-28. DOI:10.1016/j.cbpa.2018.09.027.

Bharathi, N.S., Prasad, N.G., Shakarad, M. \& Joshi, A. (2004) Correlates of sexual dimorphism for dry weight and development time in five species of Drosophila. J. Zool., 264, 87-95. DOI:10.1017/ S0952836904005576.

Bierbaum, T.J., Muellert, L.D. \& Ayala, F.J. (1989) Density-dependent evolution of life-history traits of Drosophila melanogaster. Evolution, 43, 382-392. DOI:10.1111/j.1558-5646.1989.tb04234.x.

Boonstra, R. (2013) Reality as the leading cause of stress: rethinking the impact of chronic stress in nature. Funct. Ecol., 27, 11-23. DOI:10.1111/1365-2435.12008.

Borash, D.J., Gibbs, A.G., Joshi, A. \& Mueller, L.D. (1998) A genetic polymorphism maintained by natural selection in a temporally varying environment. Am. Nat., 151, 148-156. DOI:10.1086/ 286108.

Borash, D.J., Pierce, V.A., Gibbs, A.G. \& Mueller, L.D. (2000) Evolution of ammonia and urea tolerance in Drosophila melanogaster: resistance and cross tolerance. J. Insect Physiol., 46, 763-769. DOI:10.1016/S0022-1910(99)00165-1. 
Burggren, W., Souder, B.M. \& Ho, D.H. (2017) Metabolic rate and hypoxia tolerance are affected by group interactions and sex in the fruit fly (Drosophila melanogaster): new data and a literature survey. Biol. Open, 15, 471-480. DOI:10.1242/bio.023994.

Christianson, D. \& Creel, S. (2010) A nutritionally mediated risk effect of wolves on elk. Ecology, 91, 1184-1191. DOI:10.1890/09-0221.1.

Cohen, D. (1966) Optimizing reproduction in a randomly varying environment. J. Theor. Biol., 12, 119-129. DOI:10.1016/0022-5193(66)90188-3.

Cooper, A.J. \& Plum, F. (1987) Biochemistry and physiology of brain ammonia. Physiol. Rev., 67, 440-519. DOI:10.1152/physrev.1987.67.2.440.

David, C.L., Pierce, V.A., Aswad, D.W. \& Gibbs, A.G. (1999) The effect of urea exposure on isoaspartyl content and protein L-isoaspartate methyltransferase activity in Drosophila melanogaster. Comp. Biochem. Physiol. B, 124, 423-427. DOI:10.1016/S0305-0491(99)00135-2.

De Block, M., Campero, M. \& Stoks, R. (2008) Developmental costs of rapid growth in a damselfly. Ecol. Entomol., 33, 313-318. DOI:10.1111/j.1365-2311.2007.00957.x.

De Senerpont Domis, L.N., Van de Waal, D.B., Helmsing, N.R., Van Donk, E. \& Mooij, W.M. (2014) Community stoichiometry in a changing world: combined effects of warming and eutrophication on phytoplankton dynamics. Ecology, 95, 1485-1495. DOI:10.1890/13-1251.1.

Debecker, S. \& Stoks, R. (2019) Pace of life syndrome under warming and pollution: integrating life history, behavior and physiology across latitudes. Ecol. Monogr., 89, e01332. DOI:10.1002/ecm. 1332.

Elser, J.J., Sterner, R.W., Gorokhova, E., Fagan, W.F., Markow, T.A., Cotner, J.B., Harrison, J.F., Hobbie, S.E., Odell, G.M. \& Weider, L.J. (2000) Biological stoichiometry from genes to ecosystems. Ecol. Lett., 3, 540-550. DOI:10.1111/j.1461-0248.2000.00185.x.

Fischer, K., Zeilstra, I., Hetz, S.K. \& Fiedler, K. (2005) Physiological costs of growing fast: does accelerated growth reduce pay-off in adult fitness? Evol. Ecol., 18, 343-353. DOI:10.1007/s10682004-2004-3.

Gotthard, K., Nylin, S. \& Wiklund, C. (1994) Adaptive variation in growth rate: life history costs and consequences in the speckled wood butterfly. Pararge aegeria. Oecologia, 99, 281-289. DOI:10. 1007/BF00627740.

Güneş, E. (2020) Alteration in the oxidative status of Drosophila melanogaster Meigen (Diptera: Drosophilidae) fed with a diet containing Centaurea depressa M. Bieb. (Asteraceae). Anim. Biol., 70, 227-237. DOI:10.1163/15707563-20191153.

Gutiérrez-Adán, A., Rizos, D., Fair, T., Moreira, P.N., Pintado, B., de la Fuente, J., Boland, M.P. \& Lonergan, P. (2004) Effect of speed of development on mRNA expression pattern in early bovine embryos cultured in vivo or in vitro. Mol. Reprod. Dev., 68, 441-448. DOI:10.1002/mrd.20113.

Haccou, P. \& Iwasa, Y. (1995) Optimal mixed strategies in stochastic environments. Theor. Pop. Biol., 47, 212-243. DOI:10.1006/tpbi.1995.1009.

Hawlena, D. \& Schmitz, O.J. (2010a) Physiological stress as a fundamental mechanism linking predation to ecosystem functioning. Am Nat., 176, 537-556. DOI:10.1086/656495.

Hawlena, D. \& Schmitz, O.J. (2010b) Herbivore physiological response to predation risk and implications for ecosystem nutrient dynamics. Proc. Natl Acad. Sci. USA, 107, 15503-15507. DOI:10. 1073/pnas.1009300107.

Healy, K., Ezard, T.H.G., Jones, O.R., Salguero-Gómez, R. \& Buckley, Y.M. (2019) Animal life history is shaped by the pace of life and the distribution of age-specific mortality and reproduction. Nat. Ecol. Evol., 3, 1217-1224. DOI:10.1038/s41559-019-0938-7.

Holmes, M.C., Wyrwoll, C. \& Seckl, J. (2015) Fetal programming of adult behaviour by stress and glucocorticoids. Psychoneuroendocrinology, 61, 9. DOI:10.1016/j.psyneuen.2015.07.411. 
Horváth, B. \& Kalinka, A.T. (2016) Effects of larval crowding on quantitative variation for development time and viability in Drosophila melanogaster. Ecol. Evol., 6, 8460-8473. DOI:10.1002/ ece3.2552.

Janssens, L. \& Stoks, R. (2018) Rapid larval development under time stress reduces adult life span through increasing oxidative damage. Funct. Ecol., 32, 1036-1045. DOI:10.1111/1365-2435. 13068.

Janssens, L., Van Dievel, M. \& Stoks, R. (2015) Warming reinforces nonconsumptive predator effects on prey growth, physiology and body stoichiometry. Ecology, 96, 3270-3280. DOI:10.1890/150030.1 .

Janssens, L., Op de Beeck, L. \& Stoks, R. (2017) Stoichiometric responses to an agricultural pesticide are modified by predator cues. Environ. Sci. Technol., 51, 581-588. DOI:10.1021/acs.est.6b03381.

Joshi, A. \& Mueller, L.D. (1988) Evolution of higher feeding rate in Drosophila due to densitydependent natural selection. Evolution, 42, 1090-1093. DOI:10.2307/2408924.

Joshi, A., Knight, C.D. \& Mueller, L.D. (1996) Genetics of larval urea tolerance in Drosophila melanogaster. Heredity, 77, 33-39. DOI:10.1038/hdy.1996.105.

Kain, J.S., Stokes, C. \& de Bivort, B.L. (2012) Phototactic personality in fruit flies and its suppression by serotonin and white. Proc. Natl Acad. Sci. USA, 109, 19834-19839. DOI:10.1073/pnas. 1211988109.

Kain, J.S., Zhang, S., Akhund-Zade, J., Samuel, A.D.T., Klein, M. \& de Bivort, B.L. (2015) Variability in thermal and phototactic preferences in Drosophila may reflect an adaptive bet-hedging strategy. Evolution, 69, 3171-3185. DOI:10.1111/evo.12813.

Kecko, S., Mihailova, A., Kangassalo, K., Elferts, D., Krama, T., Krams, R., Luoto, S., Rantala, M.J. \& Krams, I.A. (2017) Sex-specific compensatory growth in the larvae of the greater wax moth Galleria mellonella. J. Evol. Biol., 30, 1910-1918. DOI:10.1111/jeb.13150.

Korneev, S.A., Vavoulis, D.V., Naskar, S., Dyakonova, V.E., Kemenes, I. \& Kemenes, G. (2018) A CREB2-targeting microRNA is required for long-term memory after single-trial learning. Sci. Rep., 8, 3950. DOI:10.1038/s41598-018-22278-w.

Krams, I., Daukšte, J., Kivleniece, I., Krama, T. \& Rantala, M.J. (2011) Overwinter survival depends on immune defence and body length in male Aquarius najas water striders. Entomol. Exp. Appl., 140, 45-51. DOI:10.1111/j.1570-7458.2011.01132.x.

Krams, I., Kivleniece, I., Kuusik, A., Krama, T., Mänd, R., Rantala, M.J., Znotinna, S., Freeberg, T.M. \& Mänd, M. (2013a) Predation promotes survival of beetles with lower resting metabolic rates. Entomol. Exp. Appl., 148, 94-103. DOI:10.1111/eea.12079.

Krams, I., Kivleniece, I., Kuusik, A., Krama, T., Freeberg, T.M., Mänd, R., Vrublevska, J., Rantala, M.J. \& Mänd, M. (2013b) Predation selects for low resting metabolic rate and consistent individual differences in anti-predator behavior in a beetle. Acta Ethol., 16, 163-172.

Krams, I., Kecko, S., Kangassalo, K., Moore, F.K., Jankevics, E., Inashkina, I., Krama, T., Lietuvietis, V., Meija, L. \& Rantala, M.J. (2015) Effects of food quality on trade-offs among growth, immunity and survival in the greater wax moth (Galleria mellonella). Insect Sci., 22, 431-439.

Krams, I., Inwood, S.E., Trakimas, G., Krams, R., Burghardt, G.M., Butler, D.M., Luoto, S. \& Krama, T. (2016) Short-term exposure to predation affects body elemental composition, climbing speed and survival ability in Drosophila melanogaster. PeerJ, 4, e2314.

Krams, I., Trakimas, G., Kecko, S., Elferts, D., Krams, R., Luoto, S., Rantala, M.J., Mänd, M., Kuusik, A., Kekäläinen, J., Jõers, P., Kortet, R. \& Krama, T. (2018) Linking organismal growth, coping styles, stress reactivity, and metabolism via responses against a selective serotonin reuptake inhibitor in an insect. Sci. Rep., 8, 8599. DOI:10.1038/s41598-018-26722-9. 
Krams, I.A., Niemelä, P.T., Trakimas, G., Krams, R., Burghardt, G.M., Krama, T., Kuusik, A., Mänd, M., Rantala, M.J., Mänd, R., Kekäläinen, J., Sirkka, I., Luoto, S. \& Kortet, R. (2017) Metabolic rate associates with, but does not generate covariation between, behaviours in western stutter-trilling crickets, Gryllus integer. Proc. R. Soc. B., 284, 20162481. DOI:10.1098/rspb.2016.2481.

Lankford, T.E. Jr, Billerbeck, J.M. \& Conover, D.O. (2001) Evolution of intrinsic growth rates and energy acquisition rates. II. Trade-offs with vulnerability to predation in Menidia menidia. Evolution, 55, 1873-1881. DOI:10.1111/j.0014-3820.2001.tb00836.x.

Leal, M.C., Seehausen, O. \& Matthews, B. (2017) The ecology and evolution of stoichiometric phenotypes. Trends Ecol. Evol., 32, 108-117. DOI:10.1016/j.tree.2016.11.006.

Levy, S.F., Ziv, N. \& Siegal, M.L. (2012) Bet hedging in yeast by heterogeneous, age-correlated expression of a stress protectant. PLoS Biol., 10, e1001325. DOI:10.1371/journal.pbio.1001325.

Lewis, E. (2014) A new standard food medium. Cold Spring Harb. Protoc., 2014, pdb.rec081414. DOI:10.1101/pdb.rec081414.

Liess, A., Rowe, O., Gou, J., Thomsson, G. \& Lind, M.I. (2013) Hot tadpoles from cold environments need more nutrients - life history and stoichiometry reflects latitudinal adaptation. J. Anim. Ecol., 82, 1316-1325. DOI:10.1111/1365-2656.12107.

Lin, J.I., Mitchell, N.C., Kalcina, M., Tchoubrieva, E., Stewart, M.J., Marygold, S.J., Walker, C.D., Thomas, G., Leevers, S.J., Pearson, R.B., Quinn, L.M. \& Hannan, R.D. (2011) Drosophila ribosomal protein mutants control tissue growth non-autonomously via effects on the prothoracic gland and ecdysone. PLoS Genet., 7, e1002408. DOI:10.1371/journal.pgen.1002408.

Luoto, S. (2019) An updated theoretical framework for human sexual selection: from ecology, genetics, and life history to extended phenotypes. Adapt. Hum. Behav. Physiol., 5, 48-102. DOI:10. 1007/s40750-018-0103-6.

Luoto, S., Rantala, M.J. \& Krams, I. (2019a) England first, America second: the ecological predictors of life history and innovation. Behav. Brain Sci., 42, e205. DOI:10.1017/S0140525X19000165.

Luoto, S., Krams, I. \& Rantala, M.J. (2019b) A life history approach to the female sexual orientation spectrum: evolution, development, causal mechanisms, and health. Arch. Sex. Behav., 48, 12731308. DOI:10.1007/s10508-018-1261-0.

Maner, J.K., Dittmann, A., Meltzer, A.L. \& McNulty, J.K. (2017) Implications of life-history strategies for obesity. Proc. Natl. Acad. Sci. USA, 114, 8517-8522. DOI:10.1073/pnas.1620482114.

Mathot, K.J. \& Frankenhuis, W.E. (2018) Models of pace-of-life syndromes (POLS): a systematic review. Behav. Ecol. Sociobiol., 72, 41. DOI:10.1007/s00265-018-2459-9.

Mensch, J., Lavagnino, N., Carreira, V.P., Massaldi, A., Hasson, E. \& Fanara, J.J. (2008) Identifying candidate genes affecting developmental time in Drosophila melanogaster: pervasive pleiotropy and gene-by-environment interaction. BMC Dev. Biol., 8, 78. DOI:10.1186/1471-213X-8-78.

Meunier, C.L., Boersma, M., El-Sabaawi, R., Halvorson, H.M., Herstoff, E.M., Van de Waal, D.B., Vogt, R.J. \& Litchman, E. (2017) From elements to function: toward unifying ecological stoichiometry and trait-based ecology. Front. Environ. Sci., 5, 18. DOI:10.3389/fenvs.2017.00018.

Monaghan, P. (2008) Early growth conditions, phenotypic development and environmental change. Phil. Trans. R. Soc. B., 363, 1635-1645. DOI:10.1098/rstb.2007.0011.

Müller, J., Hense, B.A., Fuchs, T.M., Utz, M. \& Pötzsche, C. (2013) Bet-hedging in stochastically switching environments. J. Theor. Biol., 7, 144-157. DOI:10.1016/j.jtbi.2013.07.017.

Nettle, D. \& Frankenhuis, W.E. (2019) The evolution of life-history theory: a bibliometric analysis of an interdisciplinary research area. Proc. R. Soc. B., 286, 20190040. DOI:10.1098/rspb.2019.0040.

Nylin, S., Gotthard, K. \& Wiklund, C. (1996) Reaction norms for age and size at maturity in Lasiommata butterflies: predictions and tests. Evolution, 50, 1351-1358. DOI:10.2307/2410677. 
Peckarsky, B.L., Abrams, P.A., Bolnick, D.I., Dill, L.M., Grabowski, J.H., Luttbeg, B., Orrock, J.L., Peacor, S.D., Preisser, E.L., Schmitz, O.J. \& Trussell, G.C. (2008) Revisiting the classics: considering nonconsumptive effects in textbook examples of predator-prey interactions. Ecology, 89, 2416-2425. DOI:10.1890/07-1131.1.

Prasad, G. \& Joshi, A. (2003) What have two decades of laboratory life-history evolution studies on Drosophila melanogaster taught us? J. Gen., 82, 45-76. DOI:10.1007/BF02715881.

Prasad, N.G., Shakarad, M., Gohil, V.M., Sheeba, V., Rajamani, M. \& Joshi, A. (2000) Evolution of reduced pre-adult viability and larval growth rate in laboratory populations of Drosophila melanogaster selected for shorter development time. Genet. Res., 76, 249-259. DOI:10.1017/ S0016672300004754.

Preisser, E.L. \& Bolnick, D.I. (2008) When predators don't eat their prey: nonconsumptive predator effects on prey dynamics. Ecology, 89, 2414-2415. DOI:10.1890/08-0522.1.

Prokkola, J., Roff, D., Kärkkäinen, T., Krams, I. \& Rantala, M.J. (2013) Genetic and phenotypic relationships between immune defense, melanism and life-history traits at different temperatures and sexes in Tenebrio molitor. Heredity, 111, 89-96. DOI:10.1038/hdy.2013.20.

R Core Team (2018) R: a Language and Environment for Statistical Computing. R Foundation for Statistical Computing, Vienna, Austria. https://cran.r-project.org/.

Réale, D., Garant, D., Humphries, M.M., Bergeron, P., Careau, V. \& Montiglio, P.-O. (2010) Personality and the emergence of the pace-of-life syndrome concept at the population level. Philos. Trans. R. Soc. B Biol. Sci., 365, 4051-4063. DOI:10.1098/rstb.2010.0208.

Roff, D.A. (1992) The Evolution of Life Histories: Theory and Analysis. Chapman and Hall, New York, NY, USA.

Scherer, T.M. (2013) Cosolute effects on the chemical potential and interactions of an IgG1 monoclonal antibody at high concentrations. J. Phys. Chem. B., 117, 2254-2266. DOI:10.1021/ jp3091717.

Schmitz, O.J. (2013) Global climate change and the evolutionary ecology of ecosystem functioning. Ann. N. Y. Acad. Sci., 1297, 61-72. DOI:10.1111/nyas.12181.

Shakarad, M., Prasad, N.G., Rajamani, M. \& Joshi, A. (2001) Evolution of faster development does not lead to greater fluctuating asymmetry of sternopleural bristle number in Drosophila. J. Genet., 80, 1. DOI:10.1007/BF02811412.

Shakarad, M., Prasad, N.G., Gokhale, K., Gadagkar, V., Rajamani, M. \& Joshi, A. (2005) Faster development does not lead to correlated evolution of greater pre-adult competitive ability in Drosophila melanogaster. Biol. Lett., 1, 91-94. DOI:10.1098/2004.0261.

Shiotsugu, J., Leroi, A.M., Yashiro, H., Rose, M.R. \& Mueller, L.D. (1997) The symmetry of correlated selection responses in adaptive evolution: an experimental study using Drosophila. Evolution, 51, 163-172. DOI:10.1111/j.1558-5646.1997.tb02397.x.

Siepielski, A.M., Wang, J. \& Prince, G. (2014) Nonconsumptive predator-driven mortality causes natural selection on prey. Evolution, 68, 696-704. DOI:10.1111/evo.12294.

Slos, S. \& Stoks, R. (2002) Predation risk induces stress proteins and reduces antioxidant defense. Funct. Ecol., 22, 637-642. DOI:10.1111/j.1365-2435.2008.01424.x.

Solopova, A., van Gestel, J., Weissing, F.J., Bachmann, H., Teusink, B., Kok, J. \& Kuipers, O.P. (2014) Bet-hedging during bacterial diauxic shift. Proc. Natl. Acad. Sci. USA, 111, 7427-7432. DOI:10. 1073/pnas.1320063111.

Somero, G.N. \& Yancey, P.H. (1997) Osmolytes and cell-volume regulation: physiological and evolutionary principles. In: J.F. Hoffman \& J.D. Jamieson (Eds) Handbook of Physiology, Suppl. 1 Cell Physiology, pp. 441-484. Oxford University Press, Oxfords, UK. 
Spencer, K.A. (2017) Developmental stress and social phenotypes: integrating neuroendocrine, behavioural and evolutionary perspectives. Philos. Trans. R. Soc. B Biol. Sci., 372, 20160242. DOI:10.1098/rstb.2016.0242.

Sperfeld, E., Wagner, N.D., Halvorson, H.M., Malishev, M. \& Raubenheimer, D. (2017) Bridging ecological stoichiometry and nutritional geometry with homeostasis concepts and integrative models of organism nutrition. Funct. Ecol., 31, 286-296. DOI:10.1111/1365-2435.12707.

Stearns, S.C. (1992) The Evolution of Life Histories. Oxford University Press, Oxford, UK.

Stearns, S.C. \& Koella, J.C. (1986) The evolution of phenotypic plasticity in life-history traits: predictions of reaction norms for age and size at maturity. Evolution, 40, 893-913. DOI:10.1111/j.15585646.1986.tb00560.x.

Steinberg, C.E.W. (2012) Ch. 3: defense means against pathogens and parasites: reactive oxygen species. In: Stress Ecology: Environmental Stress as Ecological Driving Force and Key Player in Evolution, pp. 47-60. Springer, Dordrecht, The Netherlands. DOI:10.1007/978-94-007-2072$5 \_3$.

Sterner, R.W. \& Elser, J.J. (2002) Ecological Stoichiometry: the Biology of Elements From Molecules to the Biosphere. Princeton University Press, Princeton, NJ, USA.

Stewart, G.S. \& Smith, C.P. (2005) Urea nitrogen salvage mechanisms and their relevance to ruminants, non-ruminants and man. Nutr. Res. Rev., 18, 49-62. DOI:10.1079/NRR200498.

Svardal, H., Rueffler, C. \& Hermisson, J. (2011) Comparing environmental and genetic variance as adaptive response to fluctuating selection. Evolution, 65, 2492-2513. DOI:10.1111/j.1558-5646. 2011.01318.x.

Trakimas, G., Krams, R., Krama, T., Kortet, R., Haque, S., Luoto, S., Eichler Inwood, S., Butler, D.M., Jõers, P., Hawlena, D., Rantala, M.J., Elferts, D., Contreras-Garduño, J. \& Krams, I. (2019) Ecological stoichiometry: a link between developmental speed and physiological stress in an omnivorous insect. Front. Behav. Neurosci., 13, 42. DOI:10.3389/fnbeh.2019.00042.

van de Waal, D.B., Verschoor, A.M., Verspagen, J.M.H., van Donk, E. \& Huisman, J. (2010) Climatedriven changes in the ecological stoichiometry of aquatic ecosystems. Front. Ecol. Environ., 8, 145-152. DOI:10.1890/080178.

Van Dievel, M., Janssens, L. \& Stoks, R. (2016) Short- and long-term behavioural, physiological and stoichiometric responses to predation risk indicate chronic stress and compensatory mechanisms. Oecologia, 181, 347-357. DOI:10.1007/s00442-015-3440-1.

Van Dievel, M., Janssens, L. \& Stoks, R. (2019) Effects of pesticide exposure and predation risk on nutrient cycling and primary production. Sci. Tot. Environ., 705, 135880. DOI:10.1016/j.scitotenv. 2019.135880 .

van Straalen, N.M. (2003) Peer reviewed: ecotoxicology becomes stress ecology. Environ. Sci. Technol., 37, 324A-330A. DOI:10.1021/es0325720.

Vijiendravarma, R.K., Narasimha, S. \& Kawecki, T.J. (2011) Plastic and evolutionary responses of cell size and number to larval malnutrition in Drosophila melanogaster. J. Evol. Biol., 24, 897903. DOI:10.1111/j.1420-9101.2010.02225.x.

Wright, J., Bolstad, G.H., Araya-Ajoy, Y.G. \& Dingemanse, N.J. (2019) Life-history evolution under fluctuating density-dependent selection and the adaptive alignment of pace-of-life syndromes. Biol. Rev., 94, 230-247. DOI:10.1111/brv.12451.

Yancey, P.H. \& Siebenaller, J.F. (2015) Co-evolution of proteins and solutions: protein adaptation versus cytoprotective micromolecules and their roles in marine organisms. J. Exp. Biol., 218, 18801896. DOI:10.1242/jeb.114355. 
Zhang, C., Jansen, M., De Meester, L. \& Stoks, R. (2016) Energy storage and fecundity explain deviations from ecological stoichiometry predictions under global warming and size-selective predation. J. Anim. Ecol., 85, 1431-1441. DOI:10.1111/1365-2656.12531. 